\title{
A relationship between physical activity and healthy quality of life in students
}

\author{
Mahdi TALEBPOUR ${ }^{1}$, Masoud AGHAEI ${ }^{2}$, Amin AZIMKHANI ${ }^{3}$ \\ Sadegh ABBASIAN ${ }^{4}$, Ali ASHKANI ${ }^{5}$
}

\author{
${ }^{1}$ Department of Sport Management, Faculty of Physical Education and Sport Sciences, Ferdowsi University of Mashhad, Mashhad, Iran \\ 2 Faculty of Physical Education and Sport Sciences, Ferdowsi University of Mashhad, Khorasan razavi, Iran. \\ ${ }^{3}$ Imam Reza International University of Mashhad, Mashhad, Iran. \\ ${ }^{4}$ Faculty of Physical Education and Sport Sciences, University of Tehran, Tehran, Iran. \\ ${ }^{5}$ Faculty of Physical Education and Sport Sciences, University of Gilan, Gilan, Iran. \\ Address correspondence to Amin Azimkhani, amin.azimkhani@gmail.com
}

\begin{abstract}
The purpose of this research is to relationship between physical activity and healthy quality of life in students. Statistical population of this research involves all physically active male students in Iran from which 1352 students participated in the study as sample by using cluster sampling and sample random method. Collection data tools of this research were questionnaire according to its nature: Sharkey Physical Activity Questionnaire and Life Quality Questionnaire (WHOQOL-BREF, 2204) were used after consultation to professors, guidance and advice of authorities. As all respondents were students BREF type was selected, including four aspects of life quality plus two general questions about life and health quality evaluation. Reliability of Physical Activity Questionnaires was $r$ $=0.91$. Inferential statistics (Correlation coefficients) was also used. Results showed that there was a low significant relationship between participation in sport activities and physical health in active students $(r=0.38, p=0.000)$. There was a low significant relationship between participation in sport activities and mental- psychological condition in active students $(r=0.27, p=0.003)$. In case of social communication, there was a low significant and positive relationship between participation in sport activities in active students $(\mathrm{r}=0.32, \mathrm{p}=0.000)$. There was a low significant relationship between participation in sport activities and environmental domain in active students $(r=0.05, p=0.62)$. There was a low significant relationship between participation in sport activities and life quality in active students $(\mathrm{r}=0.24, \mathrm{p}=0.008)$. In conclusion, performing sport activities during leisure time has physical benefits, and also effective influences on overcoming mental problems. As well as invulnerability to many diseases and disorders, those who train regularly enjoy disciplined life, more performance and social relationships by acquiring freshness and further enjoy of life.
\end{abstract}

Keywords: Student, physical activity, quality of life.

\section{INTRODUCTION}

Movement is one of specifications of human life, an intention and origin in human nature and a factor for his/her growth, health and freshness. Sedentary life style causes not only failure in development, but depression, abnormal behavior and removing life freshness (1). As indicated in frequent evidences, physical activity is one of the most important factors keeping personal and social health, and those simply ignore this issue haven't yet learnt the art of life (6). Operationally, physical activity defined as follows: Physical activity includes all routine life movements such as work, leisure, exercise and all sport activities (6). Also, Health Development Center of University of
Toronto defined the life quality as facilities, opportunities and limits which any person has in his/her life and showing interaction of human and environmental factors (5).

Nowadays, continuous physical activity and suitable nutrition to achieve spiritual and mental health are a part of national health goals in developed countries, emphasizing in different declarations and encouraging all people to perform these programs to enjoy its privileges, namely increasing lifetime and improving life quality (4). Our society characterized by a fastpaced lifestyle, with obligations and stresses that affect our physical and emotional fitness. One of the most obvious reasons for becoming physically active is the 
benefit you may derive from a healthy lifestyle that includes proper exercise and nutrition. Have you noticed that it is virtually impossible to go through a day without being exposed to something involving physical fitness? We eat, sleep and go to class and some of us even try to include some form of exercise in our busy schedules. All of these make our lifestyle (8). When I talk about life style, do you know what the meaning of that is? Life style, include collection of ideas, values, manner styles, elegances, tempers and all the things about music, art, gardening and decoration. Life styles of people are not components of their personal manners. Hence, they are not unusual. But most of the people believe that they should choose their life style, freely shoal which had most essays about ....believes that, almost there is no agreement about "what are the constituents of life styles". Also in relation to this idea, Roberts believes that has not the right to determine what explanation of this concept is. Therefore enjoying a well healthy life style has a worthy importance (10).

Researchers show that Physical fitness affects the total person, including intellect, emotional stability, physical conditioning, and stress levels. Human beings are designed to be active creatures. In active man is like a still mater that falls into lassitude and indolence get sear (8). Although changes in civilization have resulted in a decrease in the amount of activity needed to accomplish the basic tasks associated with living, the human body has not changed. Therefore, it is important to be aware of the requirements for good health and recognize the importance of vigorous physical activity in your life. If you do not, your health, productivity, and effectiveness are likely to suffer to response this question that "why people should be careful about their activity?" we refer to many reasons like physical, social and psychology advantage. ) From one hand, many people suppose joyful activities as a recourse for their mentally calmness. Nowadays, it's obvious that physical activities specially sport activities, can act as a mail role in reducing mentally pressures and prompt body increase capabilities in facing of pressuring (7). Those individuals who lead a relatively sedentary style of living are more likely to suffer from CAD and are less survive a heart attack than are those who maintain an active lifestyle (3). From this case, stress has been linked to many diseases. It may also interfere with performance of daily tasks or the attainment of one's goals. Most importantly, poorly managed stress greatly reduces the quality of one's life and because everyone experiences stress, and some stress is needed to perform the daily tasks of life and, more importantly, to stimulate growth and development. In this case, researches have shown that engaging in physical activity is widely used as a means for reducing or alleviating stress. Many people who exercise report the feeling of a "high" both during and immediately following exercise. This euphoric feeling may be attributed to the release of opiate-like chemicals called endorphins in the brain. Thus to be physically fit means that a person must develop lifestyle habits that exclude negative practice such as drinking excessive amounts of alcohol, abusing other drugs, and smoking. Physical fitness involves more than exercise. The pleasure derived from smoking may be due as much to the social ritual that is associated with it as to the physiologic effects. Certainly, many young people who begin to smoke do so because they regard it as symbolic of adulthood. It has been suggested that the habit-forming nature of tobacco is largely psychologically and socially determined. As millions of smoker knows, smoking is a habit that becomes more difficult to break the more and the longer one smokes. It is known that nicotine is physically addictive (10).

Life quality is very important for students. Keeping fitness for having good life is a long way and university study period time is a part of it. The ages of 18-30 are period of construction and foundation of physical and mental fitness for a successful life, in which the persons achieve to top of adulthood and physiological performance. Therefore, youth and student periods are deemed an important period to base physical fitness throughout the lifetime. Juveniles and students consume much more time in training courses, studies, makeup activities, work and other responsibilities making them physically and mentally bored. Thus, many forget need to physical fitness. Physical disorder, mental depression and having inappropriate physical ability reduce mental effort, gradually leading performance decrease and educational decline in the universities. A student without sufficient physical fitness doesn't intend to participate some activities including swimming, mountaineering, skiing, etc, and if does, his/her performance, self-confidence and enjoy will be considerably lower than those who have higher physical fitness. Therefore, if a person is in a good physical condition, he/she will have better chance to 
achieve educational goals and his/her life will be accompanied by more creativity, health, happiness and leisure. Some authors studied relationship between participation in sport activities in leisure times, satisfaction with leisure time and satisfaction with life in students of University of Taiwan; He showed that there was a significant relationship between sport activities, life quality and satisfaction in leisure time (5). Therefore, the aim of this study was to determine the relationship between physical activity and healthy quality of life in students.

\section{MATERIAL \& METHODS}

This research is of descriptive and correlation type, carried out through field method due to the method of data collection. Statistical population of this research involves all physically active male students in Iran from which 1352 students participated in the study as sample by using cluster sampling and sample random method. Collection data tools of this research were questionnaire according to its nature: Sharkey Physical Activity Questionnaire and Life Quality Questionnaire (WHOQOL-BREF, 2204) were used after consultation to professors, guidance and advice of authorities. As all respondents were students BREF type was selected, including four aspects of life quality plus two general questions about life and health quality evaluation. Reliability of Physical Activity Questionnaires was $r=0.91$. Physical activity was measured on the basis of the physical activity index of Sharkey and Gaskill base on work of Volschenk (11). Although this questionnaire was specifically developed to determine participation in recreational activities, participants in the current study were asked to list all activities of daily living, as well as recreational activities. Therefore, the physical activity index scores obtained were much higher than the original categories developed by Sharkey and Gaskill base on work of Volschenk (11). The purpose, however, was not to compare these indexes with previous research of participation in recreational activities, but rather to obtain indexes for the senior population which includes all their daily activities. Participants marked the intensity $(1=$ Light, $2=$
Moderate, 3= Moderately heavy, $4=$ Intermittent heavy and $5=$ Heavy, exhausted), frequency ( $1=$ Once a month, $2=$ Few times a month, $3=1$ to 2 times a week, $4=3$ to 5 times a week, $5=$ Daily or almost daily), and duration ( $1=$ Under 10 minutes, $2=10$ to 20 minutes, $3=$ 20 to 30 minutes, $4=$ Over 30 minutes ) of each activity. In order to calculate the physical activity index the frequency, duration and intensity indices of each activity was multiplied and then added together. Participants were assisted by qualified professionals to complete the questionnaire accurately (11). After data collection and record, all data was analyzed by using SPSS software. Descriptive statistics was used for central tendency indices (mean, median) and distribution indices (Standard Deviation, Variance) and to draw different diagrams. Inferential statistics (Correlation coefficients such as Spearman) was also used.

\section{RESULTS}

The research findings represented that from total 1354 subjects (18-30 years old), $61.66 \%$ were students of Bachelor's Degree and 38.34\% of Master's Degree. The records of participation in sport activities in students of Bachelor's Degree were reported as $79.19 \%$ and more than one year. In addition, $78.7 \%$ students of Master's Degree were engaged to sport activities for more than one year that was the least percentage.

Findings showed that the students of Bachelor's Degree practiced sport activities for more than one year by $79.19 \%$ and for $7-9$ months by $5.14 \%$. On the other hand, $78.7 \%$ students of Master's Degree were reported more than one year sport records.

Table 1. Percentile distribution of records of sport activities of male students.

\begin{tabular}{lcccc}
\hline \multirow{2}{*}{$\begin{array}{l}\text { Records of Sport } \\
\text { Activities }\end{array}$} & \multicolumn{2}{c}{ Bachelor's Degree } & \multicolumn{2}{c}{ Master's Degree } \\
\cline { 2 - 5 } & No. & $\%$ & No. & $\%$ \\
\hline 7-9 months & 43 & 5.14 & 22 & 4.23 \\
10-12 months & 131 & 15.67 & 88 & 17.57 \\
More than 1 year & 660 & 79.19 & 408 & 78.7 \\
Total & 834 & 100 & 518 & 100 \\
& & & & \\
\hline
\end{tabular}




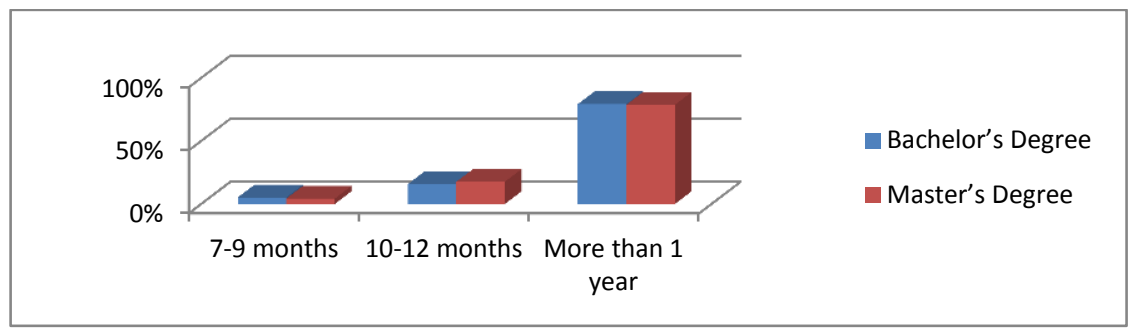

Figure 1. Percentile distribution of records of sport activities of male students.

Table 2. Percentile distribution of session's number of activity (male students).

\begin{tabular}{|c|c|c|c|c|}
\hline \multirow{2}{*}{ No. of Sessions } & \multicolumn{2}{|c|}{ Bachelor's Degree } & \multicolumn{2}{|c|}{ Master's Degree } \\
\hline & No. & $\%$ & No. & $\%$ \\
\hline Less than once/monthly & 79 & 9.52 & 63 & 12.34 \\
\hline Several times/monthly & 118 & 14.21 & 70 & 13.51 \\
\hline 1-2 times/weekly & 120 & 14.48 & 135 & 26.15 \\
\hline 3-5 times/weekly & 359 & 42.85 & 203 & 38.99 \\
\hline Everyday & 158 & 19.04 & 47 & 9.1 \\
\hline Total & 834 & 100 & 518 & 100 \\
\hline
\end{tabular}

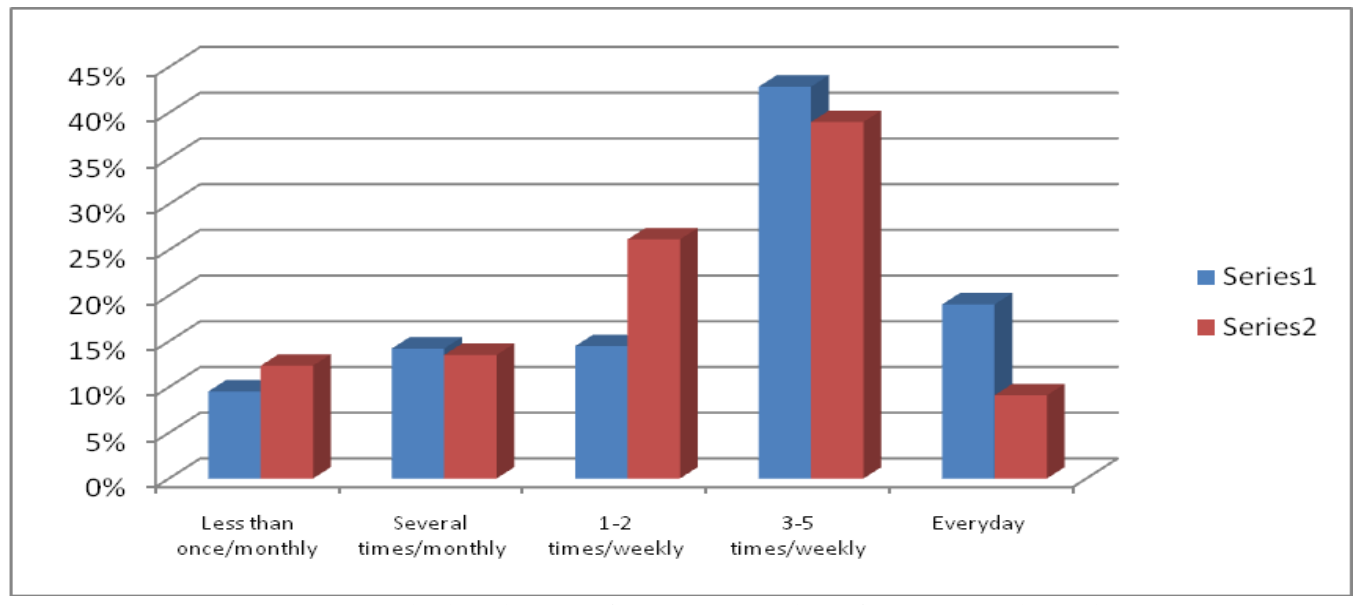

Figure 2. Percentile distribution of session's number of activity (male students).

The findings showed that $9.52 \%$ of students of Bachelor's Degree practiced sport activities once per month and $42.85 \%$ for $3-5$ times per week. In addition, $38.99 \%$ students of Master's Degree practiced sport more than 3 times per week (Table 2).

The findings showed that the duration of sport activities of male students of Bachelor's Degree more than 1 hour and students of Master's Degree for 30-60 min per session have the highest percentage (Figure 3).
Table 3. Percentile distribution of duration of any session of sport activity of male students.

\begin{tabular}{lcccc}
\hline \multirow{2}{*}{ Duration } & \multicolumn{2}{c}{ Bachelor's Degree } & \multicolumn{2}{c}{ Master's Degree } \\
\cline { 2 - 5 } & No. & $\%$ & No. & $\%$ \\
\hline & & & & \\
Less than 10 min & 79 & 9.52 & 63 & 12.09 \\
$10-20$ min & 159 & 19.04 & 57 & 11.10 \\
$20-30$ min & 123 & 14.76 & 86 & 16.60 \\
$30-60$ min & 175 & 21.04 & 160 & 30.88 \\
More than 1 hour & 298 & 35.64 & 152 & 29.33 \\
Total & 834 & 100 & 518 & 100 \\
& & & & \\
\end{tabular}




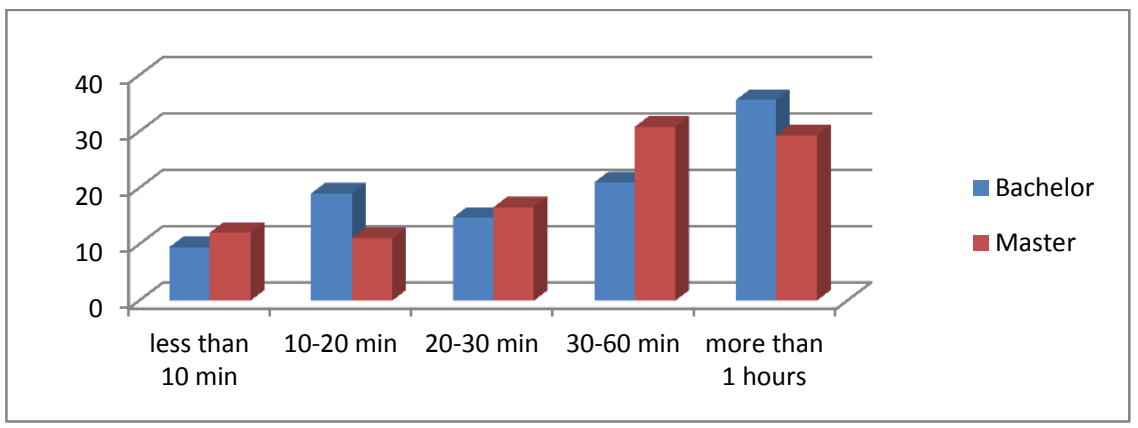

Figure 3. Percentile distribution of sessions of sport activities of male students.

Table 4. Percentile distribution of intensity of sport activity of male students.

\begin{tabular}{lcccc}
\hline \multirow{2}{*}{ Activity Intensity } & \multicolumn{2}{c}{ Bachelor's Degree } & \multicolumn{2}{c}{ Master's Degree } \\
& No. & $\%$ & No. & $\%$ \\
\hline & & & & \\
Light & 188 & 22.58 & 196 & 37.77 \\
Intermediate & 382 & 45.85 & 167 & 32.22 \\
Relatively Heavy & 160 & 19.23 & 112 & 21.60 \\
Rapid \& Heavy Respiration \& Sometimes Perspiration & 61 & 7.23 & 27 & 5.26 \\
Rapid Respiration \& High \& Continuous Perspiration & 43 & 5.11 & 16 & 3.15 \\
Total & 834 & 100 & 518 & 100 \\
\end{tabular}

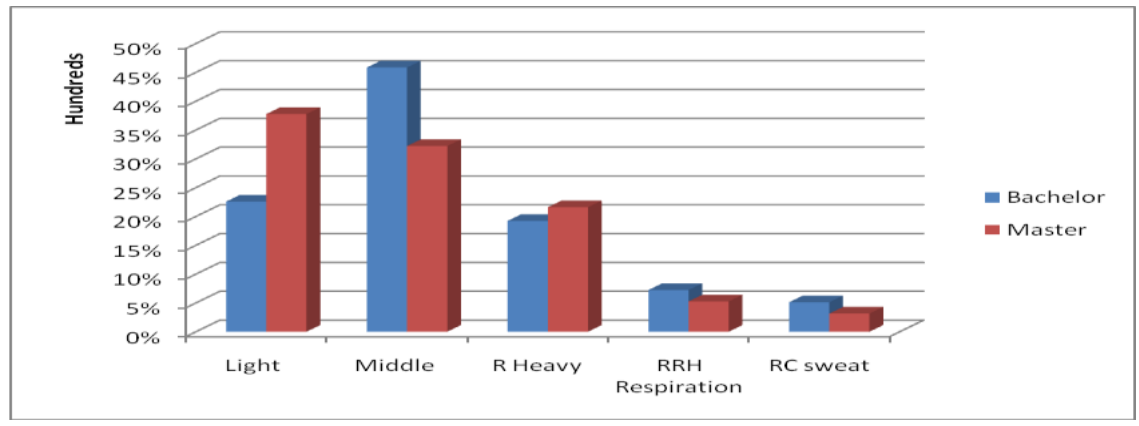

Figure 4. Percentile distribution of intensity of sport activities of male students.

The highest percentage of intensity of sport activities of students of Bachelor's Degree (47.61\%) were reported as intermediate level and students of Master's Degree (50\%) as relatively heavy. According to the results of the table, no activity of heavy intensity with rapid respiration due to higher age of students of Master's Degree was reported. Results showed that there was a low significant relationship between participation in sport activities and physical health in active students $(\mathrm{r}=0.38, \mathrm{p}=0.000)$. There was a low significant relationship between participation in sport activities and mental- psychological condition in active students $(r=0.27, p=0.003)$. In case of social communication, there was a low significant and positive relationship between participation in sport activities in active students $(r=0.32, p=0.000)$. There was a low significant relationship between participation in sport activities and environmental domain in active students $(\mathrm{r}=0.05, \mathrm{p}=0.62)$. Results showed also that there was a low significant relationship between participation in sport activities and life quality in active students $(\mathrm{r}=0.24, \mathrm{p}=0.008)$.

\section{DISCUSSION}

In this research, the effect of sport activity on health and life quality in students of Bachelor's Degree was recorded positive and significant. The results of this research are compatible to the researches carried out by Milne et al. and McAuley et al. $(5,6)$. The results of these researches showed that performing different types of exercise has physical benefits and effects on removing neural and mental problems. Stringer reported those exercising sport activities fast and slow running for one hour per day and 3 times per week 
causes develop of many physiological processes of body. Continuous engagement in sport and physical movement lead reducing blood triglyceride, increasing HDL, keeping body equilibrium, lowering blood pressure, preventing heart attacks and avoiding osteoporosis. It has been showed by many researches $(1,2,3,6,9)$. Many evidences show that there is a significant relationship between physical activity and performance abilities and health condition, preventing special diseases or reducing its intensity. It is worthy to note that for gaining benefits of physical activity require continuous and orderly participation, and will have reverse condition by reverting to inactive condition (10). In this case, continuous and orderly participation of active students in sport activities has caused reducing need of drug and treatment and students feel healthy and happy after performing sport activities. By aging, physical problems increase and role of physical activity is made considerable $(7,10)$.

Another finding of this research was positive and significant the relationship between participation in sport activities and mental condition, which was compatible to the researches, carried out by McAuley (5). Some of authors declared that physical exercises effect on behavior in two direct ways: releasing Endorphin and reducing Cortisol (a hormone excreted in blood under neural pressure). According to the specialists in body physiology, endorphins are natural drugs for reducing pains, causing deliberate senses. Physical exercises lead increasing excretion of endorphin (4). In other words, some other researchers concluded that suitable physical exercises mainly effect on increasing Serotonin (effective hormone on behavior amendment). Thus, it seems that exercise may help excretion of more endorphin and serotonin in the body and keep exercise for a more long time (2). Sport medicine researchers have recently declared that sport exercises may stabilize physiological effects of mental pressures. Change in performance of hormones, neural transferors and other chemical reactions available in body cause body reaction to mental pressures $(9,10)$. The results showed that in both age periods, participation in sport activities was more than one year. Regular and continuous exercise causes mental comfort, higher intentional power, increasing self-confidence, and more ability to make decision, all leading prevention of neural pressures especially upon problems, being deemed significance of this hypothesis. In addition, dietary and exercise can be intervention factors on effects of sport. In this research, the effect of sport activity on social communications in mid-aged persons was positive and significant, compatible to other researches $(2,3,4,8)$. In addition, we found that there was an insignificant relationship between sport domain and environmental domain. Traditions, views, insights, statistical population, different environmental areas in working place, house and place of practicing sport probably are some factors which cause this incompatibility in the results. In addition, financial condition of people can be a possible effective reason for failure in effect of sport and physical activity in environmental domain (3). The results of current research are compatible to researches carried out by Abell, Tornin and Antony in case of relation between participation in sport activities and life quality $(1,4,9)$. In this research, it was shown that the effect of sport activity on life quality of students as positive and significant, showing the positive relationship of sport to domains of life quality. The results represent that a suitable rate of sport activities is necessary for a healthy life and represent main reasons and intentions showing sport is a way towards life $(2,9,10)$.

It can be said in general conclusion that performing sport activities during leisure time has physical benefits, and also effective influences on overcoming mental problems. As well as invulnerability to many diseases and disorders, those who train regularly enjoy disciplined life, more performance and social relationships by acquiring freshness and further enjoy of life.

\section{Recommendations:}

-This research showed that there was a positive and significant relationship between sport exercise and physical health. Therefore, it recommended all persons in any age should consider sport and physical activity as a part of their leisure time;

-This research showed that there is was a positive and significant relationship between sport exercises and psychological condition. Therefore, it recommended that all persons should engage sport for more comfort at good feeling;

-This research showed that there was a positive and significant relationship between sport exercises and social communications. Therefore, it 
recommended that team groups should practice sport to provide further friendly and social relations.

\section{REFERENCES}

1. Abell JE, Hootman JM, Zack MM, Moriarty D, Helmick CG. Physical activity and health related quality of life among people with arthritis. J Epidemiol Community Health, 2005; 59(5): 380-5.

2. Brown DW, Brown DR, Heath GW, Balluz L, Giles WH, Ford ES, Mokdad AH. Associations between physical activity dose and health-related quality of life. Med Sci Sports Exerc, 2004; 36(5): 890-6.

3. Elizabeth J. Johnson. The Relationship of Environmental, Social and Individual Factors and Physical Activity Participation Level in Young Adults. Thesis for the degree of MS.c. Virginia Polytechnic Institute and State University 2008.

4. Katula JA, Rejeski WJ, Marsh AP. Enhancing quality of life in older adults: a comparison of muscular strength and power training. Health Qual Life Outcomes, 2008 13; 6: 45.

5. McAuley E, Konopack JF, Motl RW, Morris KS, Doerksen SE, Rosengren KR. Physical activity and quality of life in older adults: influence of health status and self-efficacy. Ann Behav Med, 2006; 31(1):99-103.
6. Milne HM, Gordon S, Guilfoyle A, Wallman KE, Courneya KS. Association between physical activity and quality of life among Western Australian breast cancer survivors. Psychooncology, 2007; 16(12): 1059-68.

7. Morton BG, Donohew L, Crump A D. Health communication in the prevention of alcohol, tobacco, and drogues. Health education and behavior, 1997; 23 (5): 544-54.

8. Page RM, Hammermeister J, Scanlan A, Gilbert L. Is School sport participation a protective factor against adolescent health risk behaviors? Journal of Health Education, 1968; 29(3): 186-92.

9. Rodríguez $\mathrm{A}$, Látková $\mathrm{P}$, Sun $\mathrm{Y}$. The relationship between leisure and life satisfaction: application of activity and need theory. Social Indicators Research, 2008; 86, (1): 163-175.

10. Shephard RJ, Shek PN. Associations between physical activity and susceptibility to cancer: possible mechanisms. Sports Med, 1998; 26(5): 293-315.

11. Volschenk, A. The association between physical activity, functional fitness and balance in senior citizens. Thesis for the degree of MS.c. North-West University, 2011. 